\title{
Impact of sublingual immunotherapy on seasonal asthma and skin reactivity in children allergic to Parietaria pollen treated with inhaled fluticasone propionate
}

\author{
G. B. Pajno*, D. Vita*, S. Parmiani $\dagger$, L. Caminiti*, S. La Grutta $\ddagger$ and G. Barberio* \\ *Paediatric Clinic, Messina Polyclinic Hospital, Messina University, Messina, Italy, †ALK-Abelló, Milan, Italy and $\ddagger$ Allergy Unit Children Hospital, \\ Palermo, Italy
}

\begin{abstract}
Summary
Background Immunotherapy is a recognized treatment for allergic respiratory diseases.

Objective To study the usefulness of immunotherapy in combination with optimal pharmacological therapy.

Methods Thirty-eight children (8-14 years) suffering from seasonal asthma \pm rhinoconjunctivitis due to Parietaria poorly controlled by anti-allergic drugs treatment were selected. After randomization according to a double-blind placebo-controlled design they received active sublingual immunotherapy (15 children) or placebo (15 children) for 13 months combined with inhaled fluticasone twice a day during the pollen season. Eight children were taken as control, whereas all patients were instructed to take symptomatic drugs on need. Early and late skin response to the allergen were assessed in all patients before and after treatment. Drug and symptom scores, as well as visual analogue scores (VASs) and Parietaria pollen counts were assessed during the pollen season. Results Groups were well balanced for age, gender, early and late skin response before treatment. Four children dropped out, in one case in relationship with active sublingual immunotherapy (SLIT) administration. Chest and nose symptoms, as well as drug scores and VASs were significantly better in both the active or placebo SLIT + fluticasone $(\mathrm{S}+\mathrm{F})$ as compared to the control group $(P$ between $<0.001$ and 0.043 ). Eye symptoms were significantly better in the active $\mathrm{S}+\mathrm{F}$ group as compared to control $(P=0.025)$. The VASs were significantly better in the active $\mathrm{S}+\mathrm{F}$ group as compared to the placebo $\mathrm{S}+\mathrm{F}$ group $(P=0.037)$. The early skin response decreased significantly in the active $\mathrm{S}+\mathrm{F}$ group $(P<0.001)$, whereas the late skin response changed significantly in all groups, with an increase in the placebo+fluticasone group $(P=0.019)$ and in the control group $(P=0.037)$ and a decrease $(P<0.0001)$ in the active $\mathrm{S}+\mathrm{F}$ group.

Conclusion The clinical efficacy of $\mathrm{S}+\mathrm{F}$ is equal to that of fluticasone alone, but the addition of SLIT has effects also on non-bronchial symptoms.
\end{abstract}

Keywords children, early skin response, fluticasone, late skin response, Parietaria pollen, sublingual immunotherapy, visual analog score

Submitted 3 December 2002; revised 1 August 2003; accepted 8 August 2003

\section{Introduction}

Injection allergen-specific immunotherapy (SCIT) for allergens such as grass, Parietaria, Ambrosia, mites, and hymenoptera venom has been recognized as effective on the basis of the decrease of respiratory symptoms and rescue drugs in treated patients in double-blind, placebo-controlled studies. Moreover, SCIT is now defined as an immunological response modifier, being able to positively interfere with the natural history of allergy $[1,2]$.

The mechanism of action of SCIT has not yet been defined in detail, but a switch of $\mathrm{T}$ lymphocytes from Th2 to Th1

Correspondence: Prof. Giovanni Battista Pajno, Divisione Pediatria $2^{\mathrm{a}}-$ Università di Messina Policlinico Universitario Via Consolare ValeriaGazzi 98124 Messina, Italy.

E-mail: Giovanni.Pajno@unime.it accompanied by a reduced production of IL-4, IL-5, and IL-13 cytokines has been repeatedly reported [3-6].

Over the past 10 years, the interest for the non-injection routes of administration of immunotherapy has been rapidly increasing and a large number of clinical trials have been published in the last few years (for a revision, see refs. $(1,2)$ ). Among the so-called 'local routes' of SIT, sublingual immunotherapy (SLIT) has been deeply studied and investigated from a clinical point of view and recognized as safe and effective in adults as well as children [1, 2].

All of the trials so far performed were mainly aimed at demonstrating the clinical efficacy and the safety of SLIT. However, these conclusions merely demonstrate efficacy compared to placebo.

For immunotherapy to retain a place in the treatment of seasonal asthma as additional therapy in asthmatic children already treated with inhaled steroids, we thought that a 
double-blind, placebo-controlled study in highly sensitive patients to Parietaria pollen was needed.

We chose for our trial a biologically standardized preparation already documented for efficacy and low incidence of side-effects [7-10].

\section{Materials and methods}

\section{Patients}

Thirty-eight children (age range 8-14 years) were selected according to the following criteria:

- history of seasonal asthma and rhinoconjunctivitis. The diagnosis of asthma was established on the basis of at least three doctor-diagnosed episodes separated by at least 1 week of wheezing/breath difficulty during the two previous Parietaria pollen seasons in a clinical setting where asthma was likely and conditions other than allergy had been excluded [11]

- poor symptom control in previous years despite antiallergic treatment including antihistamines, inhaled corticosteroids and nedocromil sodium for 3-4 months (i.e. almost the full pollen season)

- positive skin prick test result (weal diameter $\geqslant 5 \mathrm{~mm}$ ) to Parietaria pollen extract (Parietaria judaica - Soluprick ALK, Horsholm, Denmark);

- Specific IgE to P. judaica levels in sera of at least class 2 was determined by means of the RAST-EIA technique (Pharmacia Diagnostics AB, Uppsala, Sweden).

Patients were excluded if they or their parents reported any of the following situations:

- appreciable clinical history of sensitization to other inhalant allergens (confirmed by skin prick test and/or in vitro $\mathrm{IgE}$ analysis). Two patients belonging to the active group and one belonging to the placebo group were skintest positive to mites, but they were included because they had no clinical symptoms of allergy due to mites and showed a reactivity to methacholine $>2 \mathrm{mg} / \mathrm{mL}$ in autumn.

- a history of previous immunotherapy;

- severe asthma (forced expiratory volume in $1 \mathrm{~s}\left(\mathrm{FEV}_{1}\right)$ values below $70 \%$ of predicted values);

- a history of cardiovascular or other medical or immunological diseases.
Children showing at baseline a methacholine PC20 (concentration of inhaled methacholine that caused a $20 \%$ decrease in $\mathrm{FEV}_{1}$ ) below $2 \mathrm{mg} / \mathrm{mL}$ were also excluded so as to include only children with mild or no aspecific bronchial hyperreactivity outside the pollen season of Parietaria.

The EAACI Position Paper contraindications [12] were followed in other cases.

Demographic and clinical data of patients are shown in Table 1 .

\section{Study design}

The study was performed with the approval of the University of Messina Polyclinic Hospital Ethics Committee and the children's parents were required to sign an informed consent.

The recruitment of patient was completed during or immediately after the 1999 peak pollen season of Parietaria. Thirty out of 38 recruited children were randomized to active SLIT ( $P$. judaica) or placebo according to a double-blind design started in September 1999.

Eight asthmatic children, not treated with active or placebo SLIT, were taken as control group.

The randomization to the active (15 children), placebo (15 children), or control (8 children) group was obtained by means of a computer-generated key-code. Both SLIT groups (active and placebo) were prescribed and instructed to use rescue drugs during the peak of the following pollen season of Parietaria (i.e. from April to June 2000). They also inhaled fluticasone propionate $(50 \mu \mathrm{g}$ per actuation) twice daily, whereas the control group received only rescue drugs. All patients were asked to use allowed rescue medications regularly until improvement of symptoms.

The co-ordinator, who was blinded as to the group each child was assigned to, was in charge of patient's supervision and adjustment of rescue medications according to symptoms. He was also responsible for reporting any reaction and/or side-effects certainly or possibly related to the treatment.

\section{Immunotherapy protocol and pharmacological treatment}

The administration of SLIT to children belonging to the active or placebo group began in the first 2 weeks of September 1999 and was continued until October 2000. The

Table 1. Demographic data

\begin{tabular}{lll}
\hline & SLIT+fluticasone & Control group \\
\hline No. of patients & 15 & 15 \\
Drop-outs & 1 & 2 \\
Sex (M/F) & $7 / 8$ & $6 / 9$ \\
Age (mean in years) & 11 & 11 \\
Age (range in years) & $8-14$ & $8-14$ \\
Mean duration of allergy (years) & 4.7 & 3.11 \\
Early skin response (mean area in $\mathrm{mm}^{2}$ at baseline $\pm \mathrm{SD}$ ) & $286.54 \pm 72.66$ & $297.58 \pm 99.21$ \\
Late skin response (mean area in $\mathrm{mm}^{2}$ at baseline $\left.\pm \mathrm{SD}\right)$ & $2003.93 \pm 709.82$ & 4.1 \\
\end{tabular}

SLIT, sublingual immunotherapy. 
active treatment was standardized by a RAST-inhibition procedure in comparison with a biologically standardized inhouse reference [13] and the content of the major allergen Par $\mathrm{j} 1$ was expressed in micrograms [14]. The extract was prepared in five increasing concentrations $(0.016,0.08,0.4,2$, and $10 \mathrm{BU} / \mathrm{mL}$ ) in glycerinated and phenolated aqueous solution. The top concentration $(10 \mathrm{BU} / \mathrm{mL})$ contained $0.6 \mu \mathrm{g} / \mathrm{mL}$ of the major allergen Par $\mathrm{j} 1$. The administration schedule was started with one drop of the most diluted vial, and the amount was increased daily by one drop up to five drops. The same procedure was repeated with each of the following vials, so as to reach after 25 days the amount of five drops from the most concentrated vial. The maintenance dose of five drops of the strength $10 \mathrm{BU} / \mathrm{mL}$ was thereafter administered every other day until the end of October 2000 without changes during the pollen season. Drops had to be taken in the morning at least $15 \mathrm{~min}$ before eating and kept under the tongue for at least $2 \mathrm{~min}$ before swallowing. The placebo was indistinguishable from the active treatment for appearance, colour, and taste.

The cumulative amount of Par j 1 administered was around $20.3 \mu \mathrm{g}$, i.e. around four times the dose normally administered by the subcutaneous route for the same allergen in 13 months.

Apart from fluticasone, to be administered twice daily from April to June 2000 to all patients treated with SLIT (placebo or active), anti-allergic drugs in the form of nedocromil sodium eye drops and nasal spray were allowed on need, along with the anti-histamine loratadine and the inhaled $\beta$-agonist salbutamol. Nasal corticosteroids were not allowed.

Patients were asked to use allowed drugs regularly to control symptoms.

If symptoms developed that were uncontrolled by regular drugs, the co-ordinator could prescribe a 5-day course of prednisone $(1 \mathrm{mg} / \mathrm{kg} /$ day $)$.

\section{Assessments}

Symptom and drug scores All patients (or their parents) were instructed to record daily symptom scores from April to June on a diary card. The severity of individual symptoms was assessed on a 0-3 scale for chest (breathlessness, coughing, wheezing, and tightness), nose (sneezing, blocking, and running), eyes (itching, redness, streaming, and swelling).

Each drug administration was scored as follows: 1 point to drugs for local administration (eye drop, nasal spray, or inhaled salbutamol) and 2 points to drugs for systemic administration (loratadine, syrup or tablet, or prednisone tablet). The median weekly sum of symptom score and drug intake score was calculated for analysis.

Visual analogue score (VAS) During the pollen season each patient (or parent) was asked to indicate at 1-week intervals his/her overall chest symptoms on a VAS (scale $0-10 ; 0=$ very well, no symptoms; 10 = very bad, heavy symptoms) answering the question: 'How has your asthma been during the last 2 weeks?'

Early and late skin response Intradermal skin tests were performed in all patients before starting the treatment in September 1999 and again in October 2000 on the volar side of the forearm with a biologically standardized aqueous extract of $P$. judaica (Aquagen SQ-U, ALK-Abelló, Horsholm, Denmark).

The size of the immediate $(15 \mathrm{~min})$ and late phase ( 5 and $24 \mathrm{~h})$ cutaneous responses to the allergen $(0.02 \mathrm{~mL}$ of a 10 s.q.- $\mathrm{U} / \mathrm{mL}$ solution) or control solution $(0.02 \mathrm{~mL}$ of saline diluent) was assessed. The reaction size was calculated in $\mathrm{mm}^{2}$ taking into account the mean between the major diameter and the perpendicular diameter at its mid-point.

Pollen counts The counts of Parietaria pollen grains in the air of Messina for the observation period, expressed as weekly mean of pollen grains/cubic meter of air, were obtained from the local aerobiological service. The Burkard pollen trap (VPPS 2000, Lanzoni, Bologna, Italy) was located on the roof of a 15-m-high building inside the hospital.

Statistical analysis The analysis of non-parametric data was performed by means of the Mann-Whitney $U$-test for intergroup comparisons. Parametric data for intergroup comparisons for early and late skin reactivity were analysed by means of Student's $t$-test and the variance test. The $t$-paired test was used to analyse the change in the early and late skin reactivity in each child before and after treatment. $P$ values $<0.05$ were considered as statistically significant.

All statistical evaluations were performed with a standard statistical software (BMDP Inc., Los Angeles, CA, USA).

\section{Results}

\section{Balancing of groups}

The three experimental groups were well balanced for age, gender, and early and late skin response before treatment, as shown in Table 1.

\section{Compliance and tolerance to the treatment}

The allergen up-dosing was performed in a hospital under the supervision of a physician and with the availability of resuscitation equipment. Maintenance dose was taken at home and each patient (and parents) was regularly checked every month with reference to the correct administration of the treatment.

Thirty-four out of 38 children (89\%) completed the study. The four patients who dropped out were two from the placebo-fluticasone $(\mathrm{P}+\mathrm{F})$ group, one from the SLITfluticasone $(\mathrm{S}+\mathrm{F})$ group and one from the control group. In both cases belonging to the $\mathrm{P}+\mathrm{F}$ group, the drop out was due to family problems. The drop out from the $\mathrm{S}+\mathrm{F}$ group was due to systemic reactions (abdominal pain, shortness of breath, and wheezing) $20 \mathrm{~min}$ after drops ingestion during the maintenance phase. The patient from the control group dropped out because of the appearance of another chronic disease not related to asthma and/or allergy. These withdrawals were therefore unlikely to have biased the statistical results.

All patients who carried out the study completed diary cards and the VASs.

The planned maintenance dose (five drops from the top vial) was reached without any problem by all patients belonging to the $\mathrm{P}+\mathrm{F}$ Group and in all but one child 
belonging to the $\mathrm{S}+\mathrm{F}$ group before the pollen season. In one patient of the latter group, the maintenance dose was decreased to three drops from vial 4 because of local reactions (itching in the mouth and throat) just 1 week after the peak pollen season (2 June). Tiredness after ingestion of drops was reported by three patients belonging to the $\mathrm{S}+\mathrm{F}$ group and by two patients belonging to the $\mathrm{P}+\mathrm{F}$ group. In all cases, no adjustment of the dose was judged as necessary and all five patients completed the study with no further problems.

\section{Clinical efficacy}

Before the pollen season all patients were almost symptom free and did not take any drugs. The onset of symptoms and the need for treatment paralleled the pollen count, which is shown in Fig. 1.

Total symptom scores and chest symptoms peaked on 26 May for the control group and on May 29 for $\mathrm{S}+\mathrm{F}$ and $\mathrm{P}+\mathrm{F}$ groups, in good agreement with the average peak pollen count (2 June). Owing to the different day being taken as reference for the calculation of the weekly average value for the pollen counts (Fig. 1), for chest symptoms scores (Fig. 2a), for drug scores (Fig. 3a), and for the VAS (Fig. 4a), there was a slight apparent discrepancy between the peak of the pollen season and the top scores.

Considering the overall season, chest symptoms, nose symptoms, drugs scores, and the VASs were significantly better in both $\mathrm{S}+\mathrm{F}$ and $\mathrm{P}+\mathrm{F}$ compared with the control group ( $P$ ranging from $<0.001$ and 0.043). For eye symptoms, only the $\mathrm{S}+\mathrm{F}$ group was significantly better than the control group $(P=0.025)$. A significant difference could be shown in favour of the $\mathrm{S}+\mathrm{F}$ group as compared to the $\mathrm{P}+\mathrm{F}$ group for the VAS $(P=0.037)$ but not for chest symptoms, drug scores, eye symptoms, and nose symptoms. These results are summarized in Table 2. The behaviour of chest symptoms, drug intake, and VAS is shown in detail in Figs 2-4 ( $\mathrm{a}$ and $\mathrm{b}$ ). The difference between the control group and the others two groups began to be significant since the fifth week of the pollen season (for chest symptoms since fourth week).

In no child belonging to the $\mathrm{S}+\mathrm{F}$ group or to the $\mathrm{P}+\mathrm{F}$ group was there need for oral prednisone, whereas in four patients of the control group, a total of five courses with this drug were needed.

\section{Early and late skin response}

Table 3 summarizes the results of the skin tests in the three groups. Before treatment there was no difference either for the early $(P=0.242)$ or for the late skin response $(P=0.104)$ among groups.

The early skin response decreased significantly after treatment in the $\mathrm{S}+\mathrm{F}$ group $(-12.7 \%, P<0.001)$, whereas the decrease was not significant in both the $\mathrm{P}+\mathrm{F}$ group $(-6.8 \% ; P=0.055)$ and the control group $(-0.6 \%$; $P=0.653)$. The change in the $\mathrm{S}+\mathrm{F}$ group was statistically significant in comparison to the control group $(P=0.007)$, whereas other comparisons did not reach the statistical significance.

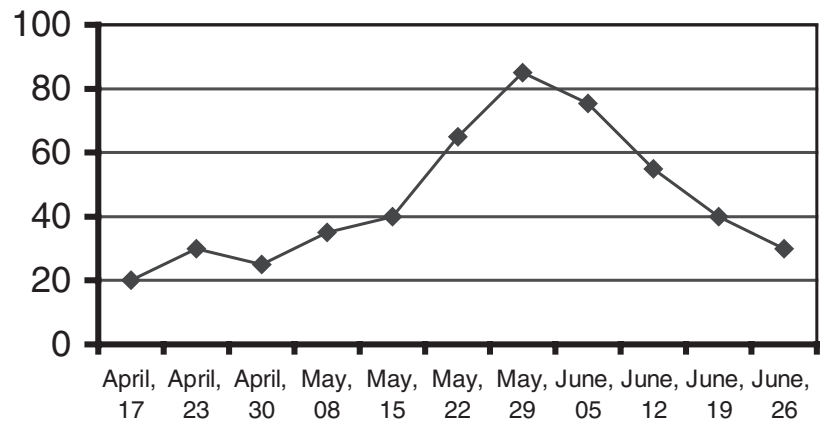

Fig. 1. Parietaria average weekly pollen counts $\left(\mathrm{grains} / \mathrm{m}^{3}\right)$ in the air of Messina (Sicily), April-June 2000.
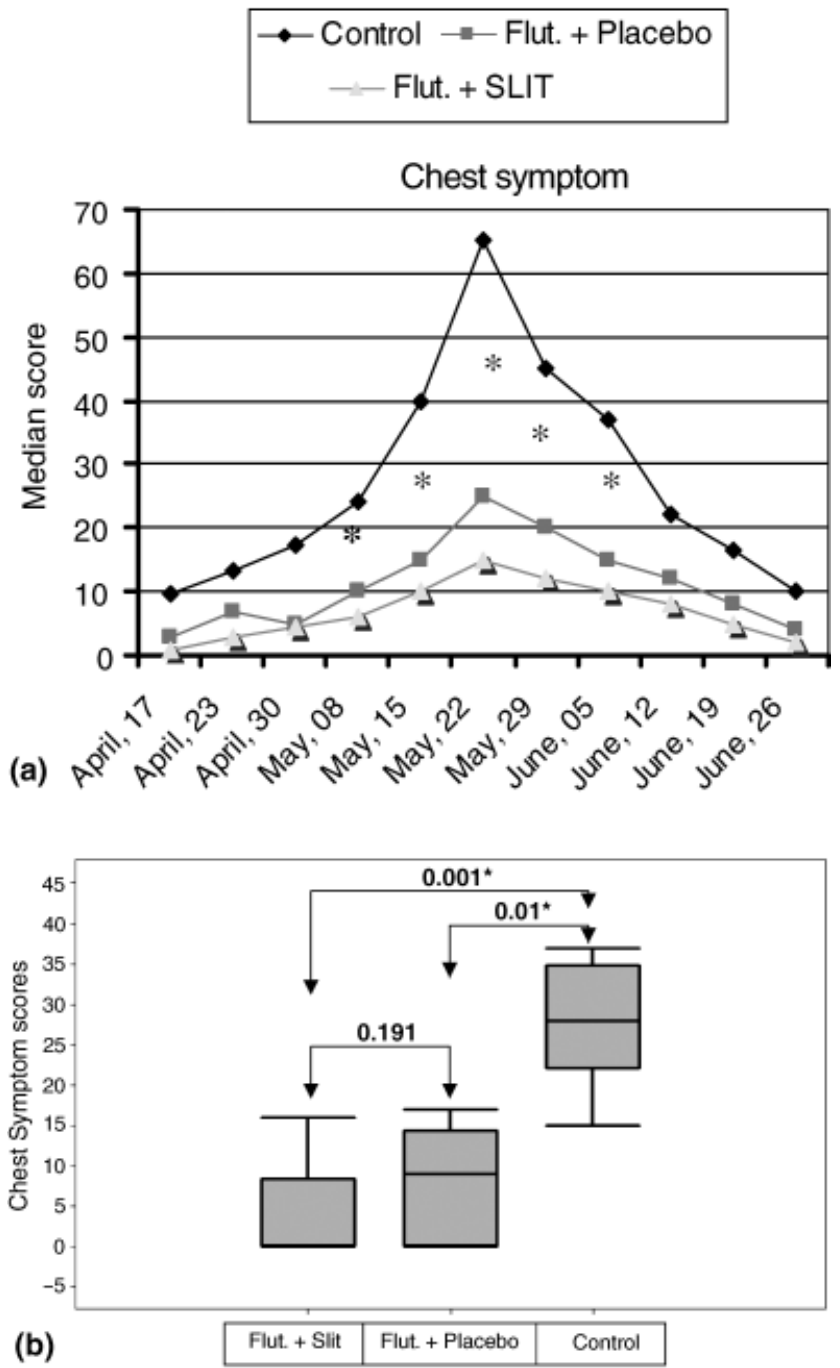

Fig. 2. (a) Medians ( \pm SEM) of the weekly sum of chest symptoms during the 2000 Parietaria pollen season in the three experimental groups, with the significant differences marked as asterisks. (b) Comparison of the overall chest symptom score (median $\pm 95 \% \mathrm{Cl}$ ) for the whole season, with the intergroup $P$-values.

The late skin response changed significantly in all groups, but it showed a different evolution in the $\mathrm{S}+\mathrm{F}$ group as compared to the $\mathrm{P}+\mathrm{F}$ group and the control group. This parameter decreased by $70.65 \% \quad(P<0.0001$, comparison 

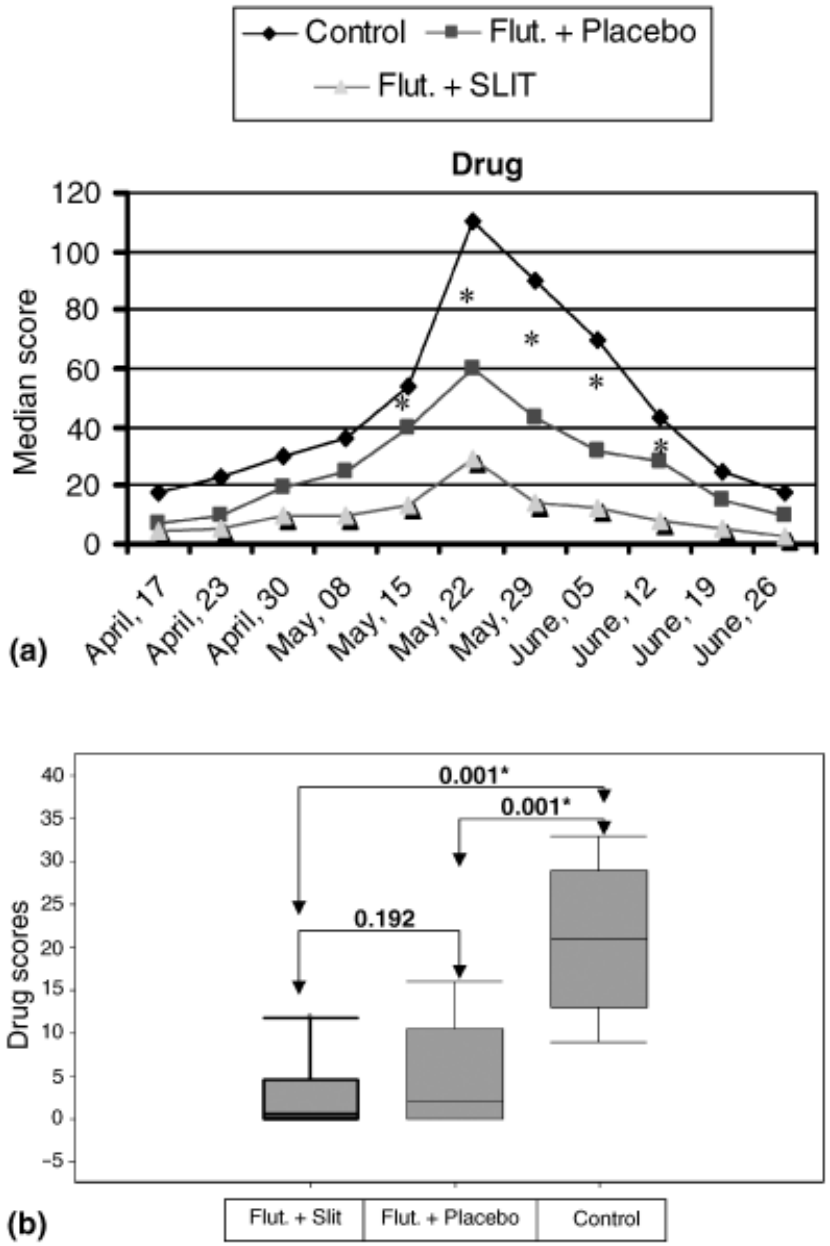

Fig. 3. (a) Medians ( \pm SEM) of the weekly sum of drug intake scores during the 2000 Parietaria pollen season in the three experimental groups, with the significant differences marked as asterisks. (b) Comparison of the overall scores (median $\pm 95 \% \mathrm{Cl}$ ) for the whole season, with the intergroup $P$-values.

before-after treatment) in the active $\mathrm{S}+\mathrm{F}$ group, whereas an increase by $10.15 \%$ in the $\mathrm{P}+\mathrm{F}$ group $(P=0.019)$ and by $11.25 \%$ in the control group $(P=0.037)$ took place.

The change in the $\mathrm{S}+\mathrm{F}$ group was statistically significant in comparison with both the $\mathrm{P}+\mathrm{F}$ group and the control group $(P<0.0001)$.

\section{Discussion}

Many well-tolerated drugs are currently available to control allergy symptoms. On the other hand, many papers have shown that SLIT is clinically effective in comparison with placebo [1, 2]. Drugs are expected to act promptly after administration, whereas specific immunotherapy is expected to exert a slower efficacy, followed by a long lasting preventive effect - not yet shown for drugs - on further sensitizations [15-17] and development of asthma [18].

The key issue that troubles most physicians treating asthmatic children and adults is how immunotherapy compares with pharmacotherapy. The pharmacological treatment is an effective and quite safe therapy but it acts

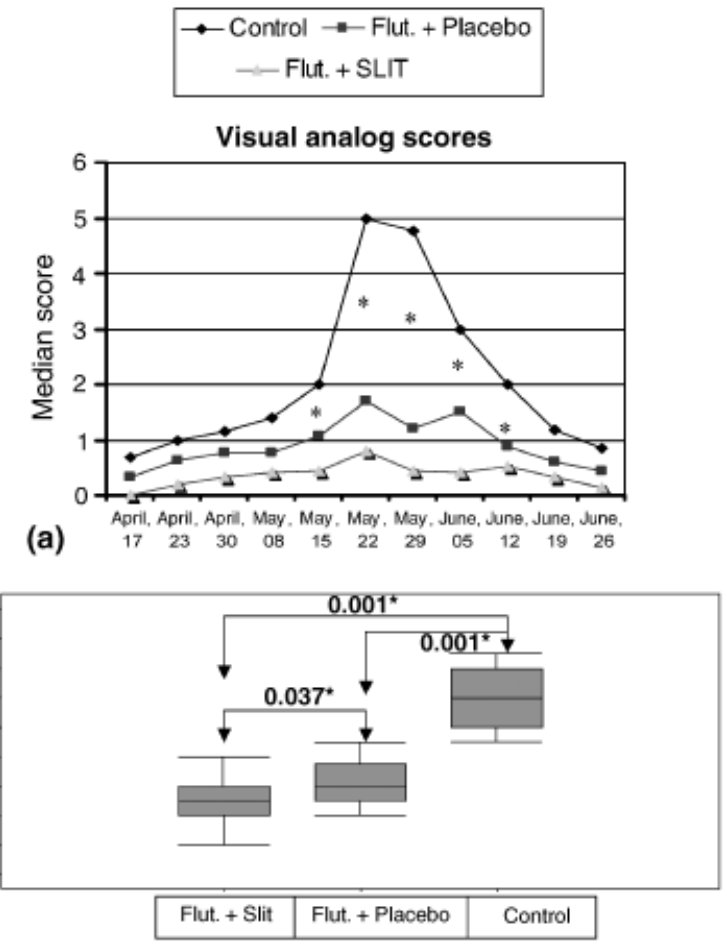

Fig. 4. (a) Median ( \pm SEM) of the weekly sum of visual analog scores during the 2000 Parietaria pollen season in the three experimental groups, with the significant differences marked as asterisks. (b) Comparison of the overall scores (median $\pm 95 \% \mathrm{Cl}$ ) for the whole season, with the intergroup $P$-values.

Table 2. Clinical scores calculated for the whole pollen season: intergroup comparisons

Parameter $\quad \mathrm{S}+\mathrm{F}$ vs. $\mathrm{P}+\mathrm{F} \quad \mathrm{S}+\mathrm{F}$ vs. control $\mathrm{P}+\mathrm{F}$ vs. control

\begin{tabular}{lccc}
\hline Non-parametric data $-P$-values for intergroup comparisons & \\
Visual analog score 2000 & $0.037^{\star}$ & $<0.001^{\star *}$ & $<0.001^{\star *}$ \\
Chest symptoms & 0.191 & $<0.001^{\star \star}$ & $<0.001^{\star \star}$ \\
Drug score & 0.192 & $<0.001^{\star \star}$ & $0.002^{\star \star}$ \\
Eye symptoms & 0.340 & $0.025^{\star}$ & 0.134 \\
Nose symptoms & 0.059 & $<0.001^{\star *}$ & $0.043^{\star}$
\end{tabular}

$S+F$, sublingual immunotherapy plus fluticasone; $P+F$, placebo plus fluticasone. *Statistically significant difference; ${ }^{* *}$ statistically high significant difference.

in a non-specific manner on allergic inflammation and its symptoms, whereas immunotherapy is an allergen-oriented treatment able to affect both immunological and inflammatory response thus modifying - especially in children - the clinical history of the allergic respiratory disease. It is therefore tempting to conclude that drugs and allergen immunotherapy are not alternative treatments but complementary strategies.

This trial was therefore planned to assess if specific immunotherapy through the sublingual route combined with the administration twice daily of fluticasone propionate may be helpful in children suffering from seasonal asthma and rhinoconjunctivitis due to $P$. judaica pollen, who experienced a poor symptom control in previous years despite an optimal pharmacological anti-allergic treatment including antihistamines, inhaled corticosteroids, and nedocromil sodium. 
Table 3. Early and late skin response: comparison among the group; mean \pm SD of the weal area

\begin{tabular}{|c|c|c|c|c|}
\hline Parameter & Group & Before & After & $P$-value \\
\hline \multicolumn{5}{|c|}{ Intragroup comparisons } \\
\hline \multirow[t]{4}{*}{ Early skin response } & $\mathrm{S}+\mathrm{F}$ & $286.54 \pm 72.66$ & $250.08 \pm 59.53$ & $<0.001^{\star *}$ \\
\hline & $\mathrm{P}+\mathrm{F}$ & $297.58 \pm 99.21$ & $277.30 \pm 84.13$ & 0.055 \\
\hline & Control & $355.97 \pm 100.5$ & $353.66 \pm 98.33$ & 0.653 \\
\hline & $\mathrm{S}+\mathrm{F}$ & $2003.93 \pm 709.82$ & $588.21 \pm 243.53$ & $<0.0001^{\star *}$ \\
\hline \multirow[t]{2}{*}{ Late skin response } & $\mathrm{P}+\mathrm{F}$ & $1926.15 \pm 817.94$ & $2121.61 \pm 819.54$ & $0.019^{\star}$ \\
\hline & Control & $2611.71 \pm 261.77$ & $2905.57 \pm 343.47$ & $0.037^{*}$ \\
\hline \multicolumn{5}{|c|}{ Intergroup comparison (ANOVA) } \\
\hline \multirow[t]{4}{*}{ Early skin response } & $\mathrm{S}+\mathrm{F}$ & $286.54 \pm 72.66$ & $250.08 \pm 59.53$ & \\
\hline & $\mathrm{P}+\mathrm{F}$ & $297.58 \pm 99.21$ & $277.30 \pm 84.13$ & 0.242 \\
\hline & Control & $355.97 \pm 100.5$ & $353.66 \pm 98.33$ & \\
\hline & $\mathrm{S}+\mathrm{F}$ & $2003.93 \pm 709.82$ & $588.21 \pm 243.53$ & \\
\hline \multirow[t]{2}{*}{ Late skin response } & $\mathrm{P}+\mathrm{F}$ & $1926.15 \pm 817.94$ & $2121.61 \pm 819.54$ & $0.025^{\star}$ \\
\hline & Control & $2611.71 \pm 261.77$ & $2905.57 \pm 343.47$ & \\
\hline
\end{tabular}

$\mathrm{S}+\mathrm{F}$, sublingual immunotherapy plus fluticasone; $\mathrm{P}+\mathrm{F}$, placebo plus fluticasone. ${ }^{*}$ Statistically significant difference; ${ }^{* *}$ statistically high significant difference.

Our data show that the addition of fluticasone propionate (combined or not to active SLIT) to the standard symptomatic anti-allergic treatment is clinically effective, as already documented by other papers $[19,20]$, because a statistically significant improvement as compared to the control group was seen for chest symptoms, nose symptoms, and drug scores. However, the combination of SLIT and fluticasone led to a statistically significant improvement as compared to the control group for eye symptoms, early skin response, and late skin response. Moreover, the use of active $\mathrm{S}+\mathrm{F}$ as compared to placebo $\mathrm{S}+\mathrm{F}$ led to a significant improvement in the VAS and in the late skin response.

The administration of SLIT in children is therefore able to further increase the clinical benefits, as judged from subjective parameters, obtainable from the standard symptomatic pharmacological treatment plus fluticasone twice a day already during the first pollen season after the beginning of the administration. The SLIT administration for 12 months was also able, in our trial, to decrease significantly two objective parameters such as the early and late skin response to the allergen. These results were obtained with a good tolerance of the treatment and using allergen dosages already documented as effective and safe in adults [7-10]. Moreover, our patients had been selected among those who had shown in the previous years a poor benefit after treatment with standard anti-allergic symptomatic drugs. It is interesting to underline that the early and the late skin response showed an opposite trend, because they increased significantly in both the control group and the placebo $\mathrm{S}+\mathrm{F}$ group whereas they significantly decreased in the active $\mathrm{S}+\mathrm{F}$ group. A decrease in the early skin reactivity after specific immunotherapy has already been documented for both injective and SLIT therapy through the skin prick test [21-24]. A decrease in the late skin response has been already documented for the injective immunotherapy [25-27], and also in one trial where very high dosages of grass allergens (about 40 times the cumulative dose administered by the subcutaneous route) were administered through the sublingual route in adults [28]. In spite of the high dosage and of the significant change in this objective parameter, this study led to inconclusive results about the clinical efficacy of the treatment. In our trial, run in children, we have been able to show that a significant change in both the early and the late skin response to the allergen can be obtained with a cumulative allergen dosage only 4-fold higher than the dose administered for the same allergen through the subcutaneous route.

In conclusion, the clinical efficacy of $\mathrm{S}+\mathrm{F}$ is equal to that of fluticasone alone, but the addition of SLIT has also effects on non-bronchial symptoms in patients under an optimal pharmacological treatment.

\section{Acknowledgements}

We thank our patients and their parents for the availability to take part in this trial and for the excellent cooperation they have shown. We are indebted to Dr Giovanni Passalacqua for reviewing the manuscript.

\section{References}

1 Bousquet J, Lockey RE, Malling HJ. Allergen immunotherapy: therapeutic vaccines for allergic diseases. WHO position paper. Allergy 1998; 53 (Suppl. 44): 1-42.

2 Bousquet J, Van Cauwemberge P, Khaltaev N. Allergic rhinitis and its impact on asthma (ARIA). J Allergy Clin Immunol 2001; 108 (Suppl. 5):S147-334.

3 Varney VA, Hamid QA, Gaga M et al. Influence of grass pollen immunotherapy on cellular infiltration and cytokine-mRNA expression during allergen-induced late-phase cutaneous responses. J Clin Invest 1993; 92:644-51.

4 Durham SR, Ying S, Varney VA et al. Grass pollen immunotherapy inhibits allergen-induced infiltration of $\mathrm{CD}^{+} \mathrm{T}$ lymphocytes and eosinophils in the nasal mucosa and increases the number of cells expressing messanger RNA for interferon-gamma. J Allergy Clin Immunol 1996; 97:1356-65.

5 Hamid Q, Schotman E, Jacobson M, Walker S, Durham S. Increases in interleukin-12 (IL-12) messenger $\mathrm{RNA}^{+}\left(\mathrm{mRNA}^{+}\right)$ cells accompany inhibition of allergen induced late skin responses following successful grass pollen immunotherapy. J Allergy Clin Immunol 1997; 99:254-60. 
6 Benjaponpitak S, Oro A, Maguire P, Marinkovich V, DeKruyff $\mathrm{RH}$, Umetsu DT. The kinetics of change in cytokine production by CD4 $\mathrm{T}$ cells during conventional allergen immunotherapy. J Allergy Clin Immunol 1999; 103:468-75.

7 Troise C, Voltolini S, Canessa A, Pecora S, Negrini AC. Sublingual immunotherapy in Parietaria pollen-induced rhinitis: a doubleblind study. J Investig Allergol Clin Immunol 1995; 5:25-30.

8 Passalacqua G, Albano M, Riccio A et al. Clinical and immunological effects of a rush sublingual immunotherapy to Parietaria species: a double-blind, placebo-controlled study. J Allergy Clin Immunol 1999; 104:964-8.

9 Purello D'Ambrosio F, Gangemi S, Isola $\mathrm{S}$ et al. Sublingual immunotherapy: a double-blind, placebo-controlled trial with Parietaria judaica extract standardized in mass units in patients with rhinoconjunctivitis, asthma, or both. Allergy 1999; 54:968-73.

10 D'Ambrosio FP, Ricciardi L, Isola S et al. Rush sublingual immunotherapy in Parietaria allergic patients. Allergol Immunopathol (Madr) 1996; 24:146-51.

11 ETAC Study Group. Allergic factors associated with the development of asthma and the influence of cetirizine in a double-blind, randomised, placebo-controlled trial: first results of ETAC. Pediatr Allergy Immunol 1998; 9:116-24.

12 EAACI. Position paper. Allergy 1993; 48 (Suppl.14):17.

13 Carreira J, Rubio M, Herrero T et al. Collaborative clinical assay of the biological potency of allergen skin tests extracts. Clin Allergy 1984; 14:503-7.

14 Carreira J, Lombardero M, Ventas P. New developments in vitro methods. Quantification of clinically relevant allergens in mass units. Arbeiten aus dem Paul Ehrlich Institut.Gustav Fischer Verlag, Stuttgart, 1994.

15 Des Roches A, Paradis L, Menardo JL, Bouges S, Daures JP, Bousquet J. Immunotherapy with a standardized Dermatophagoides pteronyssinus extract. VI. Specific immunotherapy prevents the onset of new sensitizations in children. J Allergy Clin Immunol 1997; 99:450-3.

16 Pajno GB, Barberio G, De Luca F, Morabito L, Parmiani S. Prevention of new sensitizations in asthmatic children monosensitized to house dust mites by specific immunotherapy. A six-year follow-up study. Clin Exp Allergy 2001; 31:1392-7.

17 Purello D'Ambrosio F, Gangemi S, Merendino RA, Isola S, Puccinelli P, Parmiani S. Prevention of new sensitizations in monosensitized subjects submitted to specific immunotherapy or not. A retrospective study. Clin Exp Allergy 2001; 31:1295-302.
18 Moller C, Dreborg S, Ferdousi HA et al. Pollen immunotherapy reduces the development of asthma in children with seasonal rhinoconjunctivitis (the PAT-study). J Allergy Clin Immunol 2002; 109:251-6.

19 Berger WE, Ford LB, Mahr T et al. Efficacy and safety of fluticasone dipropionate $250 \mu \mathrm{g}$ administered once daily in patients with persistent asthma treated with or without inhaled corticosteroids. Ann Allergy Asthma Immunol 2002; 89:393-9.

20 Von Berg A, Gappa M, Steinkamp G, Flit-DNCG Study Group. Fluticasone for the treatment of symptomatic bronchial asthma in children treated with sodium chromoglycate - a prospective, randomised trial. Eur J Med Res 2002; 7:257-64.

21 Tari MG, Mancino M, Monti G. Efficacy of sublingual immunotherapy in patients with rhinitis and asthma due to house dust mite. A double blind study. Allergol Immunopathol (Madr) 1990; 18:277-84.

22 Vourdas D, Syrigou E, Potamianou P et al. Double-blind, placebocontrolled evaluation of sublingual immunotherapy with standardized olive pollen extract in pediatric patients with allergic rhinoconjunctivitis and mild asthma due to olive pollen sensitization. Allergy 1998; 53:662-72.

23 Bodtger U, Poulsen LK, Jacobi HH, Malling HJ. The safety and efficacy of subcutaneous birch pollen immunotherapy - a one-year, randomised, double-blind, placebo-controlled study. Allergy 2002; 57:297-305.

24 Garcia Villalmanzo I, Hernandez MD, Campos A et al. Immunotherapy with a mass unit Parietaria judaica extract: a tolerance study with evidence of immunological changes to the major allergen Par j 1. J Investig Allergol Clin Immunol 1999; 9:321-9.

25 Varney VA, Gaga M, Frew AJ et al. Usefulness of immunotherapy in patients with severe summer hay fever uncontrolled by antiallergic drugs. BMJ 1991; 302:265-9.

26 Nish WA, Charlesworth EN, Davis TL. The effect of immunotherapy on the cutaneous late response to antigen. J Allergy Clin Immunol 1994; 93:484-93.

27 Parker WA Jr, Whisman BA, Apoliski SJ, Reid MJ. The relationships between late cutaneous responses and specific antibody responses with outcome of immunotherapy for seasonal allergic rhinitis. J Allergy Clin Immunol 1989; 84:667-77.

28 Torres Lima M, Wilson D, Pitkin L et al. Grass pollen sublingual immunotherapy for seasonal rhinoconjunctivitis: a randomized controlled trial. Clin Exp Allergy 2002; 32:507-14. 